\title{
GTPase regulator associated with the focal adhesion kinase (GRAF) transcript was down- regulated in patients with myeloid malignancies
}

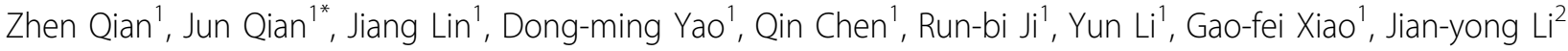

\begin{abstract}
Background: GTPase regulator associated with the focal adhesion kinase (GRAF), a putative tumor suppressor gene, is found inactivated in hematopoietic malignancies by either genetic or epigenetic abnormalities. However, the expression level of GRAF gene has not yet been studied in leukemia. The aim of this study was to investigate the expression level of GRAF gene in those patients with myeloid malignancies including acute myeloid leukemia (AML), myelodysplastic syndrome (MDS) and chronic myeloid leukemia (CML).

Methods: The expression levels of GRAF transcript were determined in 94 patients using real-time quantitative PCR (RQ-PCR). Clinical and laboratory data of these patients were collected and analyzed.

Results: The significantly decreased level of GRAF transcript was observed in three myeloid malignancies compared to controls. Within AML, there was no difference in the level of GRAF transcript among different FAB subtypes $(P>0.05)$. Difference was not observed in the amount of GRAF mRNA between CML at chronic phase and controls. As CML progressed, GRAF transcript significantly decreased. In MDS, three cases with $5 q$ deletion had lower GRAF transcript than four without $5 q$ deletion (median 0.76 vs 2.99) $(P>0.05)$.
\end{abstract}

Conclusion: our results demonstrate that the GRAF transcript is decreased in myeloid malignancies.

\section{Background}

Focal adhesion kinase (FAK), a non-receptor tyrosine kinase that resides at the sites of integrin clustering [1], plays an important role in the modulation of cell growth, proliferation, survival and migration [2]. Recently, FAK has been found to be overexpressed and/ or constitutively activated and correlated with increased motility, invasiveness, and proliferation of neoplastic cells of various tissue types [2]. Two published articles revealed that aberrant expression of $F A K$ was observed in CD34+ leukemic cells and associated with enhanced blast migration, increased cellularity and poor prognosis $[3,4]$. Le et al showed that $F A K$ silencing inhibited leukemogenesis in $B C R / A B L$-transformed hematopoietic cells [5]. Tyner et al also identified $F A K$ as one of therapeutic molecular targets in acute myeloid leukemia (AML) [6].

\footnotetext{
* Correspondence: qianjun0007@hotmail.com

'Department of Hematology, Affiliated People's Hospital of Jiangsu

University, Zhenjiang, Jiangsu 212002, China

Full list of author information is available at the end of the article
}

FAK protein is composed of an N-terminal FERM domain, a central kinase domain, and a C-terminal domain that includes the focal adhesion targeting (FAT) sequence responsible for FAK's localization to focal adhesions. Both the N-terminal and C-terminal domains have been shown to mediate FAK interaction with a variety of other proteins critical for activation of FAK by integrins or other cell surface receptors as well as FAK regulation of different cellular functions [2].

GTPase regulator associated with focal adhesion kinase (GRAF) is a newly identified protein specifically binding to the proline-rich region in the $\mathrm{COOH}$ terminus of FAK and negatively regulates the small GTPbinding protein RhoA, which is well known for its growth-promoting effect in RAS-mediated malignant transformation $[7,8]$. GRAF gene is located at chromosome $5 \mathrm{q} 31$ and its protein is ubiquitously expressed in various tissues [9]. Mutations and deletions of GRAF gene were found in some cases with AML or myelodysplastic syndrome (MDS) with a deletion 5q [9]. Furthermore, Bojesen et al [10] found that GRAF gene 
promoter was methylated in AML and MDS. The suppressed GRAF expression could be restored in leukemic cell lines by treatment with a demethyating agent and an inhibitor of histone deacytylases. However, the expression level of GRAF gene has not yet been studied in leukemia. We established the real-time quantitative polymerase chain reaction (RQ-PCR) assay with EvaGreen dye and examined the expression level of GRAF mRNA in myeloid malignancies.

\section{Materials and methods}

\section{Patients and samples}

The bone marrow mononuclear cells (BMNCs) from 94 patients with myeloid malignancies, including $72 \mathrm{AML}$, 7 MDS and 15 chronic myeloid leukemia (CML), were studied. The diagnosis and classification of AML and MDS patients were based on the French-AmericanBritish (FAB) and World Health Organization (WHO) criteria (blast $\geq 20 \%$ ) combined to immunophenotyping and cytogenetic analysis [11-15]: among AML, 12 cases of M1, 23 cases of M2, 13 cases of M3, 18 cases of M4, 5 cases of M5, 1 case of M6; among MDS, 1 case of refractory anemia with ring sideroblasts (RARS), 2 cases of refractory cytopenia with multilineage dysplasia (RCMD), 3 cases of refractory anemia with excess blasts-1 (RAEB-1), 1 case of RAEB-2. The diagnosis of CML was established according to the conventional criteria [16]: 10 cases at chronic phase (CP), 5 cases at blast crisis $(\mathrm{BC})$.

The clinical characteristics of patients were listed in Table 1. Karyotypes were analyzed using conventional R-banding method. Karyotype risk in AML and MDS was classified according to the reported studies [15,17]. $t(15 ; 17)$ was also included in the group of low risk. BMNCs, collected from 3 donors of bone marrow transplantation, 5 patients with immune thrombocytopenia (ITP), and 13 with iron deficiency anemia (IDA), were used as controls.

\section{Immunophenotyping studies}

Erythrocyte-lysed whole BM samples from 61 AML patients were analyzed by flow cytometry using a panel of MoAbs in triple stainings [phycoerythrin (PE)/fluorescein isothiocyanate (FITC)/Peridin chlorophyll (PerCP)]: IgG1-FITC; IgG2a-PE; CD2-PE; CD4-FITC; CD7-FITC; CD10-FITC; CD11b-PE; CD13-PE; CD19-PE; CD38-PE; CD45-PerCP; CD117-PE; HLA-DR-FITC (Becton Dickinson, USA); CD14-PE; CD22-FITC; CD33-FITC; CD34-FITC; CD36-FITC (Beckman Coulter, USA). Data acquisition and analysis were performed on a FACScalibur flow cytometer (Becton Dickinson) using Cell-Quest software. Identification of leukemic cells was performed using CD45 intensity versus SSC dot plots. Antigen expression was considered to be positive when the percentage of positive leukemic cells was equal or greater than $20 \%$.

\section{Preparation of RNA and CDNA synthesis}

BMNCs were separated using Lymphoprep and lysed with Trizol (In Vitrogen, Carlsbad, CA, USA) according to the manufacturer's instructions. Two micrograms of total RNA was reverse transcribed to cDNA in a total reaction volume of $40 \mu \mathrm{l}$ containing $5 \times$ buffer, dNTPs $10 \mathrm{mM}$ each, random hexamers $10 \mu \mathrm{M}$, RNAsin 80 units and 200 units of MMLV reverse transcriptase (MBI Fermentas, USA). Samples were incubated for $10 \mathrm{~min}$ at $25^{\circ} \mathrm{C}, 60 \mathrm{~min}$ at $42^{\circ} \mathrm{C}$, and then stored at $-20^{\circ} \mathrm{C}$.

\section{RQ-PCR}

RQ-PCR was performed using EvaGreen dye (BIOTIUM, Hayward, CA, USA) on a 7300 Thermo cycler (Applied Biosystems, Foster City, CA, USA). Real-time fluorescent data were collected and analyzed with SDS 1.3 software (Applied Biosystems, Foster City, CA, USA). The baseline fluorescence intensities were fixed at cycles $6-15$ by default and 0.01 was set as the threshold to determine the cycle threshold $\left(C_{T}\right)$ value. The

Table 1 clinical and laboratory features of patients with myeloid malignancies

\begin{tabular}{|c|c|c|c|}
\hline Parameter & AML & CML & MDS \\
\hline Age, median (range) (years) ${ }^{a}$ & $54(2-86)$ & $52(11-75)$ & $63(39-85)$ \\
\hline Sex (male/female) & $44 / 28$ & $8 / 7$ & $5 / 2$ \\
\hline WBC $\left(\times 10^{9} /\right)^{a}$ & $7.5(0.3-203.6)$ & $83.4(2.8-168.7)$ & $3.6(1.6-12.2)$ \\
\hline Haemoglobin $(\mathrm{g} / \mathrm{dl})^{\mathrm{a}}$ & $71(24-123)$ & $91(50-134)$ & 64(46-91) \\
\hline Platelet count $\left(\times 10^{9} / /\right)^{a}$ & $40(3-447)$ & $200(20-850)$ & $50(10-926)$ \\
\hline \multicolumn{4}{|l|}{ Cytogenetics } \\
\hline Good & 22 & & 3 \\
\hline Intermediate & 35 & & 3 \\
\hline Poor & 8 & & 1 \\
\hline CD34(+/-) & $35 / 26$ & & \\
\hline GRAF level ${ }^{a}$ & $3.88(0.01-169.75)^{b}$ & $23.51(0.01-157.42)^{c}$ & $10.20(0.25-45.90)^{b}$ \\
\hline
\end{tabular}

WBC, white blood cells; ${ }^{a}$ Median (range); ${ }^{\mathrm{b}} P<0.001$, compared with control; ${ }^{\mathrm{c}} P=0.030$, compared with control; 
primers of GRAF and housekeeping gene $A B L$ were designed against GenBank-published sequences (NM_015071 and NM_14752) with the software Primer Express 2.0 (Applied Biosystems, Foster City, CA, USA). The primer sequences are as follows: GRAF forward 5'ATTCCAGCAGCAGCTTACA-3', reverse 5'-GATGAG GTGGGCA TAGGG-3', $A B L$ forward 5'-TCCTCCA GCTGTTATCTGGAAGA-3', reverse 5'-TCCAACGA GCGGCTTCAC-3', with expected PCR products of 166 bp and $118 \mathrm{bp}$, respectively. PCR was performed in a final volume of $25 \mu \mathrm{l}$, containing $100 \mathrm{ng}$ of cDNA, $0.2 \mathrm{mM}$ of dNTP, $4 \mathrm{mM}$ of $\mathrm{MgCl}_{2}, 0.4 \mu \mathrm{M}$ of primers, $1.2 \mu \mathrm{l}$ of EvaGreen, 1.0 U of Taq DNA Polymerase (MBI Fermentas, USA). Amplification consisted of an initial denaturation step of $94^{\circ} \mathrm{C}$ for 4 min followed by 40 cycles of a denaturation step at $94^{\circ} \mathrm{C}$ for $30 \mathrm{~s}$, an annealing step at $62^{\circ} \mathrm{C}$ for $30 \mathrm{~s}$, an extension step of $72^{\circ} \mathrm{C}$ for $30 \mathrm{~s}$, and an fluorescence collection step at $82^{\circ} \mathrm{C}$ for 30 $\mathrm{s}$, followed by a final extension of $72^{\circ} \mathrm{C}$ for $10 \mathrm{~min}$. Sterile $\mathrm{H} 2 \mathrm{O}$ without cDNA used as no-template control (NTC) in each assay. The copies of GRAF and $A B L$ mRNA were calculated automatically by the software. The relative amount of GRAF was normalized using the following formula: $\mathrm{N}_{G R A F}=$ (copies of GRAF/copies of $A B L) \times 100$. Amplified RQ-PCR products from three samples were sequenced (Shanghai GeneCore BioTechnologies Co., Ltd., China).

\section{Statistical analyses}

Statistics was performed using the SPSS 13.0 software package (SPSS, Chicago, IL). The Kruskal-Wallis test (multiple groups) and Mann-Whitney $U$-test (two groups) were employed to compare the difference between patient groups and controls. The correlation between the level of GRAF transcript and the sex, age, hematologic parameters, FAB subtypes and karyotypic groups was calculated by Spearman's rho correlation analyses. A $P$-value $<0.05$ was considered significant.

\section{Results}

\section{GRAF expression in controls and AML patients}

The level of GRAF transcript in controls was 14.49126.85 (median 56.04). The significantly decreased level of GRAF transcript was observed in different myeloid malignancies (Table 1, Figure 1). There was no correlation between GRAF mRNA amount and the sex, age, peripheral white blood cell count, hemoglobin level, and platelet count $(P>0.05)$. The association of GRAF levels with cytogenetic abnormalities or CD34 antigen expression was also not observed in AML patients $(P>0.05)$. Within AML, there was no difference in the level of GRAF transcript among different FAB subtypes $(P>0.05)$.

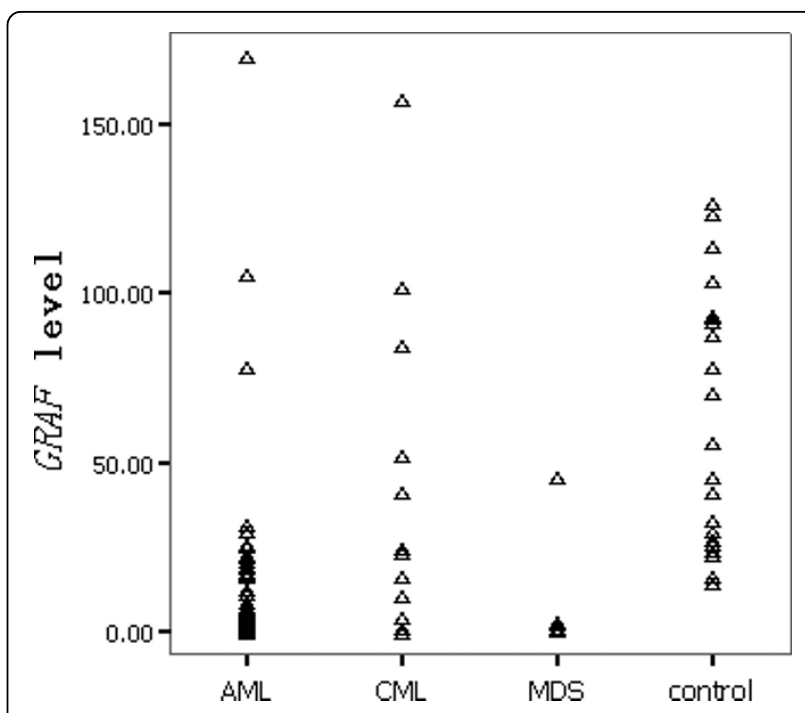

Figure 1 Scatterplot showing varying levels of GRAF transcript in patients with different myeloid malignancies and controls

\section{GRAF expression in CML patients}

The median levels of GRAF transcript in CML patients at $\mathrm{CP}$ and $\mathrm{BC}$ were $46.82(1.08-157.42)$ and 10.69 (0.0123.51), respectively (Figure 2). There was no difference in GRAF transcript amount between CML patients at $\mathrm{CP}$ and controls $(P>0.05)$. However, the amount of GRAF mRNA in CML at BC was significantly lower than that in cases at $\mathrm{CP}$ and that in controls $(P=0.028$ and $<0.001$, respectively).

\section{GRAF expression in MDS patients}

Among MDS patients, three cases were identified with deletions of $5 \mathrm{q}(5 \mathrm{q}-)$ (Table 2). The level of GRAF

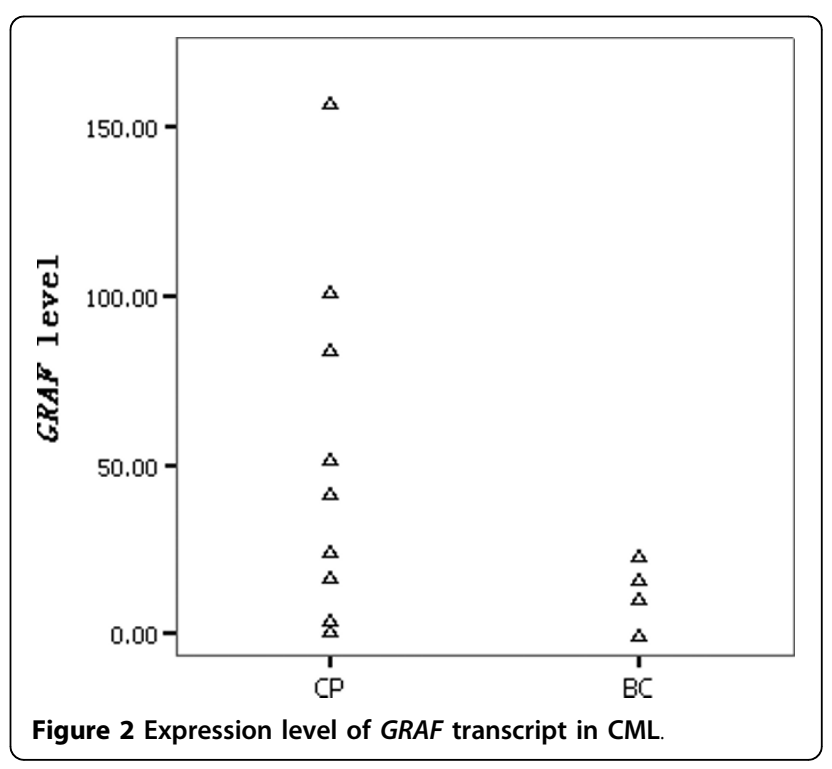


Table 2 Clinical and laboratory characteristics of patients with MDS

\begin{tabular}{cccllc}
\hline No. & Sex & Age (year) & Diagnosis & Karyotype & GRAF level \\
\hline 1 & $F$ & 51 & RAEB-2 & $46, X X$ & 2.76 \\
2 & $F$ & 63 & RCMD & $46, X X$, del(20)(q11) & 45.90 \\
3 & $M$ & 67 & RAEB-1 & $46, X Y$ & 3.22 \\
4 & $M$ & 74 & RARS & $46, X Y$, del(5)(q13q33) & 0.49 \\
5 & $M$ & 85 & RAEB-1 & $46, X Y$, del(5)(q13q33) & 0.76 \\
6 & $M$ & 39 & RCMD & $46, X Y$ & 0.25 \\
7 & $M$ & 41 & RAEB-1 & $44-45, X Y$, del(5)(q13q33), $-7,-15,-21[\mathrm{cp}]$ & 1.02 \\
\hline
\end{tabular}

transcript was lower in these cases $(0.49-1.02$, median $0.76)$ than the other four cases without $5 q-(0.25-45.90$, median 2.99), however, statistical difference was not observed $(P>0.05)$.

\section{Discussion}

In this study, we demonstrated that the expression level of GRAF transcript was decreased in primary leukemic cells of all types of myeloid malignancies. Bojesen et al [10] found that GRAF promoter was hypermethylated in 38\% cases with AML and MDS but not in healthy individuals, however, they did not detect the GRAF transcript in primary leukemic cells of AML and MDS. GRAF contains a centrally located GTPaseactivating protein (GAP) domain, followed by a serine/ proline rich domain and a carboxy-terminal Srchomology 3 (SH3) domain. GRAF acts as a negative regulator of RhoA because the GRAF GAP domain enhances GTP hydrolysis of both Cdc42 and RhoA in vitro [7]. Rho family GTPases play a role in the growth control besides regulating the organization of the actin cytoskeleton [18,19]. RhoA inhibits p21Cip1, p27Kip and p16Ink4 activities, permitting cell cycle progression [20-24]. Furthermore, RhoA has been shown involved in the regulation of apoptosis, migration, proliferation, differentiation $[18,19]$ : for example, in vitro, constitutively active RhoA can stimulate transformation. In normal epithelia, RhoA contributes to the generation of epithelial polarity and junction assembly and function but also affects epithelial disruption during tumor progression [25]. Recently, clinical studies have revealed the correlation of increased expression of RhoA and invasion, metastasis and progression of several solid tumors including liver, bladder, esophageal, head and neck, ovary, gastric, testicular, lung and breast carcinomas [18]. As an upstream regulator, the loss of function of GRAF might prevent the physiologic down-regulation of RhoA and lead to the repression of $\mathrm{p} 21$. Then, the GRAF-defective cell will be driven into the $S$ phase [9]. Several mechanisms, including translocations, allelic loss, insertions and promoter methylation observed in AML and MDS, can lead to the inactivation of GRAF $[9,10]$.
The mechanisms responsible for the disease progression of CML remained poorly understood. Recent studies have suggested that several alterations promote this progress, including differentiation arrest caused by the suppression of translation of the transcription factor CEBP $\alpha$ induced by the BCR-ABL oncoprotein in CML cell, increasing genomic instability in CML cell resulting from the reduced capability of genome surveillance system, telomere shortening and loss of tumor suppressor gene (TSG) such as TP53, retinoblastoma 1, CDKN2A, $D A P K 1$ and others [16,26,27]. Interestingly, we found that GRAF transcript was further down-regulated during CML progression. p210 Bcr-Abl, containing a centrally located Rho-specific guanine nucleotide exchange factors (RhoGEF) domain, affects the actin cytoskeleton assembly and thereby the cellular adhesion and migration by RhoA signaling pathway [28]. Further studies are required to elucidate the function of GRAF and $R h o A$ in the pathogenesis and progression of CML.

Our preliminary results showed that MDS with $5 \mathrm{q}$ deletion might have lower expression of GRAF than those without $5 \mathrm{q}$ deletion. Deleted $5 \mathrm{q}$ is a one of common chromosomal abnormalities in AML and MDS. Although GRAF maps telomeric to the previously delineated commonly deleted 5(q31) region, Borkhardt et al found that one allele of GRAF was consistently lost in all studied 10 patients with $5 \mathrm{q}$ deletion and with either MDS or AML [9]. Besides GRAF deletion, abnormal methylation of GRAF promoter was also observed in AML and MDS [10]. These results suggested that haploinsufficiency (i.e., decreased GRAF mRNA expression) caused by deletion of GRAF allele or promoter methylation might be instrumental in the development and progression of hematopoietic malignancies.

In conclusion, GRAF mRNA is decreased in myeloid malignancies. Whether the GRAF expression level could improve the stratification or prognostication of patients with myeloid diseases should be further addressed in future studies.

\section{Acknowledgements}

This study was supported by Jiangsu Province's Key Medical Talent Program (RC2007035) and Social Development Foundation of Zhenjiang (SH2006032). 


\section{Author details}

'Department of Hematology, Affiliated People's Hospital of Jiangsu University, Zhenjiang, Jiangsu 212002, China. ${ }^{2}$ Department of Hematology, The First Hospital of Nanjing Medical University, Jiangsu Provincial People's Hospital, Nanjing, Jiangsu, 210029, China.

\section{Authors' contributions}

QJ and LJY designed the study, analyzed the data and wrote the manuscript; QZ, L, YDM and CQ performed all experiments; JRB, LY and XGF gave assistance with technical performance and contributed to the writing of the manuscript. All authors read and approved the final manuscript.

\section{Competing interests}

The authors declare that they have no competing interests.

Received: 19 July 2010 Accepted: 12 August 2010

Published: 12 August 2010

\section{References}

1. Sieg DJ, Hauck CR, llic D, Klingbeil CK, Schaefer E, Damsky CH, Schlaepfer DD: FAK integrates growth-factor and integrin signals to promote cell migration. Nat Cell Biol 2000, 2:249-256.

2. Zhao J, Guan JL: Signal transduction by focal adhesion kinase in cancer. Cancer Metastasis Rev 2009, 28:35-49.

3. Recher C, Ysebaert L, Beyne-Rauzy O, Mansat-De Mas V, Ruidavets JB, Cariven P, Demur C, Payrastre B, Laurent G, Racaud-Sultan C: Expression of focal adhesion kinase in acute myeloid leukemia is associated with enhanced blast migration, increased cellularity, and poor prognosis. Cancer Res 2004, 64:3191-3197.

4. Tavernier-Tardy E, Cornillon J, Campos L, Flandrin P, Duval A, Nadal N, Guyotat D: Prognostic value of CXCR4 and FAK expression in acute myelogenous leukemia. Leuk Res 2009, 33:764-768.

5. Le Y, Xu L, Lu J, Fang J, Nardi V, Chai L, Silberstein LE: FAK silencing inhibits leukemogenesis in BCR/ABL-transformed hematopoietic cells. Am J Hematol 2009, 84:273-278.

6. Tyner JW, Walters DK, Willis SG, Luttropp M, Oost J, Loriaux M, Erickson H, Corbin AS, O'Hare T, Heinrich MC, Deininger MW, Druker BJ: RNAi screening of the tyrosine kinome identifies therapeutic targets in acute myeloid leukemia. Blood 2008, 111:2238-2245.

7. Hildebrand JD, Taylor JM, Parsons JT: An SH3 domain-containing GTPaseactivating protein for Rho and $\mathrm{Cdc} 42$ associates with focal adhesion kinase. Mol Cell Biol 1996, 6:3169-3178.

8. Sahai E, Olson MF, Marshall CJ: Cross-talk between Ras and Rho signalling pathways in transformation favours proliferation and increased motility. EMBO I 2001, 20:755-766.

9. Borkhardt $A$, Bojesen $S$, Haas OA, Fuchs U, Bartelheimer D, Loncarevic IF, Bohle RM, Harbott J, Repp R, Jaeger U, Viehmann S, Henn T, Korth P, Scharr D, Lampert F: The human GRAF gene is fused to MLL in a unique $\mathrm{t}(5 ; 11)(\mathrm{q} 31 ; \mathrm{q} 23)$ and both alleles are disrupted in three cases of myelodysplastic syndrome/acute myeloid leukemia with a deletion $5 \mathrm{q}$. Proc Natl Acad Sci USA 2000, 97:9168-9173.

10. Bojesen SE, Ammerpohl O, Weinhäusl A, Haas OA, Mettal H, Bohle RM, Borkhardt A, Fuchs U: Characterisation of the GRAF gene promoter and its methylation in patients with acute myeloid leukaemia and myelodysplastic syndrome. Br J Cancer 2006, 94:323-332.

11. Bennett JM, Catovsky D, Daniel MT, Flandrin G, Galton DA, Gralnick HR, Sultan C: Proposed revised criteria for the classification of acute myeloid leukaemia. A report of the French-American-British Cooperative Group. Ann Intern Med 1985, 103:620-625.

12. Bennett JM, Catovsky D, Daniel MT, Flandrin G, Galton DA, Gralnick HR, Sultan C: Proposals for the classification of the myelodysplastic syndromes. Br J Haematol 1982, 51:189-199.

13. Vardiman JW, Harris NL, Brunning RD: The World Health Organization (WHO) classification of the myeloid neoplasms. Blood 2002, 100:2292-2302.

14. Lo Coco F, Foa R: Diagnostic and prognostic advances in the immunophenotypic and genetic characterization of acute leukaemia. Eur J Haematol 1995, 55:1-9.

15. Slovak ML, Kopecky K, Cassileth PA, Harrington DH, Theil KS, Mohamed A, Paietta E, Willman CL, Head DR, Rowe JM, Forman SJ, Appelbaum FR: Karyotypic analysis predicts outcome of preremission and postremission therapy in adult acute myeloid leukemia: a Southwest Oncology Group/ Eastern Cooperative Oncology Group Study. Blood 2000, 96:4075-4083.

16. Qian J, Wang YL, Lin J, Yao DM, Xu WR, Wu CY: Aberrant methylation of the death-associated protein kinase 1 (DAPK1) CpG island in chronic myeloid leukemia. Eur I Haematol 2009, 82:119-123.

17. Greenberg P, Cox C, LeBeau MM, Fenaux P, Morel P, Sanz G, Sanz M, Vallespi T, Hamblin T, Oscier D, Ohyashiki K, Toyama K, Aul C, Mufti G, Bennett J: International scoring system for evaluating prognosis in myelodysplastic syndromes. Blood 1997, 89:2079-2088.

18. Karlsson $R$, Pedersen $E D$, Wang Z, Brakebusch C: Rho GTPase function in tumorigenesis. Biochim Biophys Acta 2009, 1796:91-98.

19. Benitah SA, Valerón PF, van Aelst L, Marshall CJ, Lacal JC: Rho GTPases in human cancer: an unresolved link to upstream and downstream transcriptional regulation. Biochim Biophys Acta 2004, 1705:121-132.

20. Aznar S, Fernández-Valerón P, Espina C, Lacal JC: Rho GTPases: potential candidates for anticancer therapy. Cancer Lett 2004, 206:181-191.

21. Vidal A, Millard SS, Miller JP, Koff A: Rho activity can alter the translation of p27 mRNA and is important for RasV12-induced transformation in a manner dependent on p27 status. J Biol Chem 2002, 277:16433-16440.

22. Seasholtz TM, Zhang T, Morissette MR, Howes AL, Yang AH, Brown JH: Increased expression and activity of RhoA are associated with increased DNA synthesis and reduced p27(Kip1) expression in the vasculature of hypertensive rats. Circ Res 2001, 89:488-495.

23. Olson MF, Paterson HF, Marshall CJ: Signals from Ras and Rho GTPases interact to regulate expression of p21 ${ }^{\text {Waf1/Cip1 }}$. Nature 1998, 394:295-299.

24. Liberto M, Cobrinik D, Minden A: Rho regulates p21(CIP1), cyclin D1, and checkpoint control in mammary epithelial cells. Oncogene 2002, 21:1590-1599.

25. Vega FM, Ridley AJ: Rho GTPases in cancer cell biology. FEBS Lett 2008, 582:2093-2101.

26. Melo JV, Barnes DJ: Chronic myeloid leukaemia as a model of disease evolution in human cancer. Nat Rev Cancer 2007, 7:441-453.

27. Calabretta B, Perrotti D: The biology of CML blast crisis. Blood 2004, 103:4010-4022.

28. Sahay S, Pannucci NL, Mahon GM, Rodriguez PL, Megjugorac NJ, Kostenko EV, Ozer HL, Whitehead IP: The RhoGEF domain of p210 Bcr-Abl activates RhoA and is required for transformation. Oncogene 2008, 27:2064-2071.

doi:10.1186/1756-9966-29-111

Cite this article as: Qian et al: GTPase regulator associated with the focal adhesion kinase (GRAF) transcript was down-regulated in patients with myeloid malignancies. Journal of Experimental \& Clinical Cancer Research 2010 29:111.

\section{Submit your next manuscript to BioMed Central and take full advantage of:}

- Convenient online submission

- Thorough peer review

- No space constraints or color figure charges

- Immediate publication on acceptance

- Inclusion in PubMed, CAS, Scopus and Google Scholar

- Research which is freely available for redistribution

Submit your manuscript at www.biomedcentral.com/submit
C Biomed Central 